\title{
Restraint Use in the Management of the Elderly with Dementia in Hospital
}

\author{
Lim SC ${ }^{* 1}$, Poon $\mathrm{WH}^{2}$ \\ ${ }^{1 *}$ Senior Consultant, Department of Geriatric Medicine, Changi General Hospital, Singapore \\ ${ }^{2}$ Chief Nurse, Nursing Service, Ang Mo Kio-Thye Hua Kwan Hospital, Singapore \\ *Correspondence to: Lim SC, Senior Consultant, Department of Geriatric Medicine, Changi General Hospital, Singapore; E-mail: si_ching_lim@cgh.com.sg
}

Received: November 24, 2016; Accepted: December 07, 2016; Published: December 14, 2016;

\begin{abstract}
There is widespread use of physical restraints among the elderly with dementia in residential setting and acute hospitals. Physical restraints are means to limit a person's freedom of movement. The commonest indications for restraining an elderly are to manage agitated and aggressive elderly at risk of harming themselves or others, reduce falls risk and avoid dislodgement of medical devices. Physical restraints have not been proven to benefit the patients and have been reported to be associated with injuries, falls and deaths. The ethical dilemma associated with restraint use is often conflicting. There are active moves to reduce/ remove physical restraints use in institutions among the elderly with dementia and challenging behaviours. The use of restraints should be considered a last resort when there is imminent danger and where other means of management have failed and patients being restrained should be reviewed regularly to have the restraint removed at the earliest opportunity.
\end{abstract}

Key words: physical restraints, behavioral and psychological symptoms, dementia, elderly with dementia

\section{Introduction}

With the rapid aging population in the world, there is an increasing trend of people living with dementia. Reports have estimated that there will be about 131.5 million people with dementia by 2050 . Dementia has a huge economic impact, costing US $\$ 818$ billion in total worldwide, and it will become a trillion dollar disease by 2018. In many parts of the world, there is a growing awareness of dementia, but a diagnosis of dementia can bring with it stigma and social isolation. Today, it is estimated that $94 \%$ of people living with dementia residing in low and middle income countries are cared for at home. These are regions where health and care systems often provide limited or no support to people living with dementia or to their families. [1]

In an acute hospital setting, people with dementia have more than three times hospital stays per year compared to the elderly without dementia. Utilisation of healthcare resources for chronic medical conditions, such as stroke, cancers, diabetes, coronary heart disease is increased among the elderly with dementia. [2]

The elderly patients with dementia in an acute hospital are at high risk of being restrained, especially if they require assistance with their activities of daily living (ADLs) and the most frequently cited reasons for restraint use are for the protection of the patients themselves, and to prevent interference with medical therapies. Physical restraint usage is between $33-68 \%$ among the elderly in hospitals. [3]

\section{The elderly with dementia and behavioural symptoms}

Dementia is a group of prolonged, debilitating neuropsychiatric disorders which affect the patients and their family for years after diagnosis. The presence of behavioural and psychological symptoms of dementia occurs among $98 \%$ of individuals with dementia at some point during their disease progression. Behavioral and Psychological Symptoms of Dementia (BPSD) has been associated with more rapid decline in cognition, greater impairment of ADLs, caregiver burden leading to caregiver burnout, diminished quality of life for caregivers and patients and early institutionalisation. [4-7] The caregiver for a person with dementia has been described as living a 36 hour day by Mace and Rabins, resulting in physical, emotional and mental fatigue. [8]

The spectrum of behavioural abnormalities in BPSD can be divided into behavioural or psychological abnormalities, as shown in (Table 1). Currently, there is no recommended single treatment for BPSD. Clinicians use a combination of drugs such as Cholinesterase inhibitors, anti-depressants, anti-convulsants with mood stabilising properties, antipsychotics, benzodiazepines and N-Methyl-Daspartate receptor antagonist with varying degree of success. The elderly are more susceptible to side effects of these medications, including anticholinergic side effects with agitation and sedation, extrapyramidal side effects and orthostatic hypotension contributing to fall risk. [9] The non-pharmacological treatment of BPSD with an aim to reduce medication side effects have been studied with music therapy, art therapy, aromatherapy, touch therapy, orientation therapy, physical exercises and tailored activities have been tried with variable success rate due to heterogeneity of the study designs and further research is required. [10]

Behavioural symptoms in dementia suggest the presence of underlying unmet needs and must therefore be looked at as means of communication as cognitive abilities decline. The unmet needs include physical causes like medical illness and pain or psycho social and emotional needs. Agitation signifies progression of dementia. 
At the middle stages of dementia where verbal communication is diminishing, verbally agitated behaviours such as repetitions, cursing or screaming, are common. In severe stages of dementia, physically agitated behaviours predominate because they have lost the abilities to communicate verbally. [11] Agitated behaviours may be a reflection of others' behaviour where the elderly with dementia does not comprehend or does not want. Agitation is associated with poor outcome for health and general wellbeing. Agitated behaviour places an elderly at risk of harm on themselves, caregivers and often leads to early institutionalisation. Nurses often see an agitated elderly as a challenge and feel helpless to intervene. [12]

Table 1. Spectrum of BPSD

\begin{tabular}{|l|l|}
\hline \multicolumn{1}{|c|}{ Behavioural } & \multicolumn{1}{c|}{ Psychological } \\
\hline $\begin{array}{l}\text { Agitation-e.g. restless, pacing, disrobing } \\
\text { inappropriately. }\end{array}$ & Mood disorders- anxiety, depression \\
\hline $\begin{array}{l}\text { Aggression-hitting, biting, scratching, } \\
\text { pushing, throwing objects, destroying } \\
\text { property, tearing items. }\end{array}$ & Changes in personality \\
\hline $\begin{array}{l}\text { Verbal aggression- cursing, swearing, } \\
\text { shouting, screaming }\end{array}$ & Psychosis- delusions, hallucination \\
\hline Wandering & Pathological crying \\
\hline Repetition & Apathy \\
\hline Sexual disinhibition & Irritability \\
\hline $\begin{array}{l}\text { Urination/ defecation-at inappropriate time } \\
\text { and place }\end{array}$ & Mood lability \\
\hline Hoarding & Elation \\
\hline
\end{tabular}

\section{Causes of BPSD- Theoretical models}

Cohen-Mansfield applied theoretical models to analyse the causes of BPSD. The problematic behaviours in dementia may arise from various causes such as 1.) unmet needs, 2.) behavioural/ learning models and 3.) environmental factors.

Unmet needs among the person with dementia are frequently not obvious to the caregivers. Among some of these include inadequately treated pain, toileting needs, thirst, hunger, sensory deprivation, boredom and loneliness. Use of restraints causes restriction in independence, social isolation and may worsen behaviour. Assisting the person with dementia with proper eye wear and hearing aids, regular toilet rounds, assistance for physical exercise, meaningful activities and meals, providing sensory stimulation like pet therapy, music therapy, social interactions may reduce agitation.

The ABC model of behaviours consists of antecedent events which are the stimuli leading to the behaviour and consequences of the behaviours. The consequences reinforce certain behaviours in response to the antecedents. Many problem behaviours are learned through reinforcements by staff who paid attention when problem behaviours are displayed. To modify the behaviours requires new learning experiences which change the antecedent and behaviour.

The environmental theory suggests that persons with dementia are more vulnerable to environmental stimuli and they have a lower threshold at which their behaviour changes in response. The persons with dementia lose their coping abilities progressively and find the environmental changes increasingly more stressful. The threshold for stress also lowers progressively. When environmental stimuli exceed the stress threshold, they are more likely to show anxiety and inappropriate behaviours. [13]

Cohen-Mansfield suggested that the different models may interact and complement each other. For example, an environmental stimulus (unfamiliar surrounding) may cause an unmet need to surface (getting lost looking for toilets, bedroom) which may account for different behaviours (resulting in pacing, agitation, incontinence, etc) among different people. The different models provide the basis for intervention and the effectiveness of interventions indicates the usefulness of these models.

\section{Indications for Physical restraints}

The commonest reasons for restraints use are prevention of falls, protection of medical devices, means to control behaviour like aggression and wandering and to stabilise patient's position. The traditional management for an agitated elderly is to restrain them either physically or chemically or ignored. [12] A physical restraint is any physical or mechanical method attached or adjacent to the body which restricts one's freedom or movement or normal access to one's body. [14] There are various types of physical restraints available, among the commoner ones used in the hospitals and nursing homes include body vest, pelvic vest, limb ties, mittens, lap belts, bed rails and tray tables. The most commonly used restraints are bed rails and belts. The predictors for restraints usage are, poor mobility, cognitive impairment, high physical dependency, organisational characteristics and high fall risk. [15]

\section{Fall prevention and restraints- is there a role?}

The elderly with dementia are more likely to be put on physical restraints because of poor memory for recent events, behavioural symptoms, delirium, language dysfunction with impaired abilities to communicate needs. Falls risk increases in dementia due to unsteady gait, poor safety awareness and poor judgement. [16] In a hospital setting, inpatient falls are considered a risk management issue and carries with it guilt, self-blame and possible litigations. There are measures in place in hospitals to reduce falls such as early fall risk assessment with policies for fall precautions and provision of a safe environment. Among some of the data published on nurses' attitude towards restraint usage among the elderly, most nurses feel negatively towards restraining the elderly. However, they do believe there is a need for restraints mainly to reduce falls. This causes moral conflicts. Generally, when in doubt, most nurses were in favour of restraints. [17]

Staffs frequently have a sense of false security when they put an elderly on restraints to protect them from falls. Physical restraints have not been shown to reduce falls. In fact, restraints like body vests have been associated with higher fall risk and fractures. Tinetti showed that usage of physical restraints resulted in three fold increase likelihood of serious fall-related injures compared to the unrestrained elderly, after adjusting for other factors. [18, 19] Patients being restrained often struggle to get out and in doing so, they often become more agitated with reports of patients getting trapped between mattress and bed rail, some of the patients become more restless and attempt to climb over bed rails resulting in falls from greater height. The struggling also causes fatigue and prolonged restraints imposed immobility causes 
significant muscular atrophy which is accelerated compared to the younger patients, leading to falls, functional decline and needing longer periods of rehabilitation to restore. Muscle strength reduces by up to $5 \%$ a day. Repeated episodes of atrophy and recovery may lead to permanent loss of skeletal muscle mass and strength with disability. $[20,21]$

Once a physical restraint has been deemed unnecessary, removal of physical restraints has not been shown to increase falls among nursing home residents. In fact, restraint removal has positive effects on the welfare and independence of the elderly, with changes in behaviour and reductions in the number of antipsychotic prescriptions. [22, 23]

\section{Harm associated with physical restraints}

Despite the widespread use of physical restraints in Nursing homes and hospitals, the safety and efficacy have not been well studied. Currently, there is no evidence that restraint prevent falls or secondary injuries. The types of restraint related injuries reported include direct injuries where the physical restraint causes direct physical damage to skin, with skin tear and haematomas being the commonest. Other reported direct injuries include nerve injuries, asphyxiation and sudden death. Sudden deaths occurred among elderly patients with cardiac conditions who struggled to be free of physical restraints. Vests have been associated with asphyxiation leading to death, the mechanisms included patients hanging by vest over bed rails, with vest caught against the neck. Retrospective reviews of death certificates identified deaths associated with restraints use among people in beds or chairs. Bed rails have been associated with getting heads trapped between mattress and bed rails. [24]

Indirect injuries associated with restraint use include increased mortality, falls, longer hospital length of stay, physical deconditioning, contractures, nutritional impairment, pressure ulcers, bowel and urinary incontinence. Patients put on restraints for more than 4 days were at higher risks of developing pressure sores and nosocomial infections. [24]

Apart from physical injuries, restraining the elderly with no or moderate cognitive impairment in a residential setting has been associated with greater decline in cognition. The elderly with severe cognitive impairment seemed to be unaffected. [25] Physical restraints have also been reported to be associated with more unsociable behaviours, depression, fear and regression. [26]

\section{The ethics of using physical restraints}

There will be occasions where the patient may be of danger to himself or others around them, and there is a need of using physical restraints to limit harm by restricting patient's movement. However, sometimes physical restraints are misused in circumstances for staff's convenience or punishing patient for their bad behaviour.

\section{Autonomy}

Respect for autonomy is the belief in individual freedom. The individual has a right to make his/her own decisions and intentionally act upon them, without being coerced or manipulated. The individual also has a right to liberty or self-determination, without controlling influence or interference from others. In people with dementia, there is progressive loss in the decision making capacity. For making a decision on medical treatment, we as healthcare providers need to ensure that the medical information provided is clear and understood. There is capacity to make a decision without coercion or deception. In the cases where the patient has limited decision making capacity, principles of beneficence and non-maleficence outweighs autonomy. [27]

In the situation of treating elderly with behavioural issues and dementia, there is often coercion or deception involved in the behavioural management, like hiding medications in food, putting up seat belts or bed rails when the elderly with dementia are not complying with treatment and yet failed to understand the risk to their own safety if they fail to comply with instructions. The paternalistic view that healthcare professionals are specialists who know best and the patients under their care, in their sick roles are expected to comply. Compliance itself suggests a requirement to yield in the context of cure. The patients are expected to believe their caregivers have the best knowledge, determine the best outcome and act in the patient's best interest, and often, the interventions are beyond question. Nursing staffs are often faced with the dilemma of weighing the patient's autonomy and their safety especially when there is a shortage of staff to provide better supervision. In nursing and medical practice, when the expectation is for patient to comply, there may be coercion or deception involved and autonomy is often compromised. [28]

\section{Beneficence and nonmaleficence}

In health care, healthcare workers are to act for the patients' benefits, maximising utility and taking into account risks and cost incurred in doing a procedure or action. Among patients who may have difficulties making decisions, autonomy may be constrained by beneficence. Beneficence is a continuum from preventing or removing harm to doing good or promoting a person's welfare.

Nonmaleficence in medical ethics means do no harm, remove harm and facilitate good. In the case of physical restraint use among the elderly, there is evidence to show that restraints cause more harm than benefits. [24-26] Since there is no evidence for effectiveness, it is questionable to classify restraint as therapeutic. It is therefore important to ask if restraint use violate the principle of nonmaleficence.

The principle of beneficence to an agitated elderly is rarely absolute where safety is concerned. It is unclear whether restraint actually confers safety to the patients. Instances where immediate safety of patient/ staff is threatened, beneficence is in conflict with autonomy. Other than in those instances where safety is really a legitimate concern, we need to consider the principles of beneficence and nonmaleficence carefully. [29]

\section{The ethical struggle- clinicians left with "dirty hands"}

In situations where the patient is at risk of imminent danger to himself or staff, restraining them may be the unavoidable and right thing to do. This may give rise to conflict in professional practice. The argument goes that patient may benefit from restraint and this justifies the risk of harm. This paradox constitutes the philosophical 
dilemma of dirty hands which essentially means to commit a moral wrong in order to do what is right. Healthcare workers often have to use coercive methods to treat patients with dementia, or getting them to comply with treatment, leaving them with a complex moral stain in order to do "right" for the patients. [30]

\section{Is it possible to have a restraint free environment?}

The Federal Drug Authority put forth warnings of safety and alert on vests, limb restraints and bedrails in 1992 and 1995. The legal standard has changed their stand from liability from failure to restrain to one that presumes appropriate care relying on interventions other than restraints.

In the United States, moves to care for the elderly without using restraints include, better tolerance of behavioural symptoms, complete ban of restraints in homes, nurses' low acceptance for restraint use, improving staff knowledge about restraint hazards, minimising falls risk, understanding and responding to behaviours. Education and leadership of a gerontological trained nurse was helpful in reducing not only restraint use, there was no increase in staff number, psychoactive drug prescription or serious falls-related injuries. [31]

Individualised care plans with psychosocial interventions like anticipation of needs, physiological needs like pain management, planned activities and environmental interventions such as low beds, contoured chairs, based on the individual patient's needs were also effective in reducing restraint use. The individual's needs to assist with activities of daily living with walking aids, sensory aids are helpful to determine the changes in functional abilities from baseline. Premorbid toileting habits were adhered to minimise agitation from discomfort. Medical interventions like oxygen tubes or feeding tubes are minimised or disguised to reduce discomfort and distract the patient. Behavioural patterns and psychosocial needs were explored with the family to provide an idea of changes from baseline and to reduces the stresses of environmental changes in causing agitation and restlessness. [32] Environmental modifications like contoured chairs, low beds are safer and more comfortable for the elderly. Bedside alarms and commodes are recommended to reduce injuries and reduce restraint use. [33]

\section{Summary}

Physical restraints should be eliminated for the care of elderly with dementia. The risks of harm for physical restraints far outweigh the benefits. Careful, individualised assessment and individualised care plans addresses needs which are often unmet among the elderly with dementia. Education and guidance from a specialist trained nurse has been shown to be successful. A restraint free care environment is possible only if there is support from the organisation.

\section{References}

1. World Alzheimer Report 2015. The analysis of prevelance, incidence, cost and trends. Published By Alzheimer's Disease International (ADI), London. August 2015.

2. Alzheimer's Association (2015) Alzheimer's disease facts and figures. Alzheimers Dement 11: 332-384. [crossref]

3. Gallinagh R, et al. (2002) the use of physical restraints as a safety measure in the care of the older people in four rehabilitation wards: findings from an exploratory study. Int J Nurs Stud 39: 147-156.
4. Lyketsos CG, Carrillo MC, Ryan JM, Khachaturian AS, Trzepacz P, et al. (2011) Neuropsychiatric symptoms in Alzheimer's disease. Alzheimers Dement 7: 532 539. [crossref]

5. Stern Y, Mayeux R, Sano M, Hauser WA, Bush T (1987) Predictors of disease course in patients with probable Alzheimer's disease. Neurology 37: 1649-1653. [crossref]

6. González-Salvador T, Lyketsos CG, Baker A, Hovanec L, Roques C, et al. (2000) Quality of life in dementia patients in long-term care. Int J Geriatr Psychiatry 15: 181-189. [crossref]

7. Hersch EC, Falzgraf S (2007) Management of the behavioral and psychological symptoms of dementia. Clin Interv Aging 2: 611-621. [crossref]

8. Mace NL, Rabins PV (2000) The 36-hour Day: A family guide to Caring for People Who have Alzheimer Disease, Related dementias and Memory Loss.

9. Zaudig M (2000) A risk-benefit assessment of risperidone for the treatment of behavioural and psychological symptoms in dementia. Drug Saf 23: 183-195. [crossref]

10. Martini de Oliveira A, et al. (2015) Non pharmacological interventions to reduce behavioural and psychological symptoms of dementia: A systematic review. BioMed Research International.

11. Cohen-Mansfield J (2001) Nonpharmacologic interventions for inappropriate behaviors in dementia: a review, summary, and critique. Am J Geriatr Psychiatry 9: 361-381. [crossref]

12. Dewing J (2010) Responding agitation in people with dementia. Nurs Older People 22: 18-25. [crossref]

13. Hall GR (1994) Caring for people with Alzheimer's disease using the conceptual model of progressively lowered stress threshold in the clinical setting. Nurs Clin North Am 29: 129-141. [crossref]

14. Healthcare financing Administration, 42 CFR Section 483.1 and 42 CFR.13€; 2000 .

15. Hamers JP, Huizing AR (2005) Why do we use physical restraints in the elderly? Z Gerontol Geriatr 38: 19-25. [crossref]

16. Cotter VT (2005) Restraint free care in older adults with dementia. Keio J Med 54: 80-84. [crossref]

17. Mohler R, Meyer G (2014) Attitudes of nurses towards the use of physical restraints in geriatric care: a systematic review of qualitative and quantitative studies. Int $J$ Nurs Stud 51: 274-288. [crossref]

18. Huabin Luo, et al. (2011) Physical restraint use and falls in nursing homes: A comparison between residents with and without dementia. Americal Journal of Alzheimer's Disease \& Other Dementias 26(1): 44-50.

19. Tinetti ME, Liu WL, Ginter SF (1992) Mechanical restraint use and fall-related injuries among residents of skilled nursing facilities. Ann Intern Med 116: 369-374. [crossref]

20. Creditor MC (1993) Hazards of hospitalization of the elderly. Ann Intern Med 118: 219-223. [crossref]

21. Kasper CE (2003) Sketetal muscle atrophy. In: Carrieri-Kohlman V et al. Pathophysiological phenomena in nursing: human responses to illness. St. Louis: Saunders 389-412.

22. Capezuti E, Strumpf NE, Evans LK, Grisso JA, Maislin G (1998) The relationship between physical restraint removal and falls and injuries among nursing home residents. J Gerontol A Biol Sci Med Sci 53: M47-52. [crossref]

23. Tortosa MÁ, Granell R2, Fuenmayor A2, Martínez M3 (2016) Effects of a physical restraint removal program on older people with dementia in residential care. Rev Esp Geriatr Gerontol 51: 5-10. [crossref]

24. Evans D, Wood J, Lambert L (2003) Patient injury and physical restraint devices: a systematic review. J Adv Nurs 41: 274-282. [crossref]

25. Burton LC, German PS, Rovner BW, Brant LJ (1992) Physical restraint use and cognitive decline among nursing home residents. J Am Geriatr Soc 40: 811-816. [crossref]

26. Castle NG (2006) Mental health outcomes and physical restraint use in nursing homes. Adm Policy Ment Health 33: 696-704. [crossref]

27. Woods B, Pratt R (2005) Awareness in dementia: ethical and legal issues in relation to people with dementia. Aging Ment Health 9: 423-429. [crossref]

28. Lejman E, Westerbotn M, Pöder U, Wadensten B (2013) The ethics of coercive treatment of people with dementia. Nurs Ethics 20: 248-262. [crossref]

29. Mohr WK (2010) Restraints and the code of ethics: An uneasy fit. Arch Psychiatr Nurs 24: 3-14. [crossref]

30. De Wijze S (2005) Tragic remorse- The anguish of Dirty Hands. Ethical Theory and Moral Practice.

31. Patterson JE, Strumpf NE, Evans LK (1995) Nursing consultation to reduce restraints in a nursing home. Clin Nurse Spec 9: 231-235. [crossref]

32. Strumpf, et al. (1998) Restraint free care: Individualised approaches for frail elders. NY: Springer.

33. Hospital Bed Safety Workgroup (2003) Clinical guidance for the assessment and implementation of bed rails in hospitals, long term care facilities, and home care settings. Crit Care Nurs $Q$ 26: 244-262. [crossref]

\section{Citation:}

Lim SC, Poon WH (2016) Restraint Use in the Management of the Elderly with Dementia in Hospital. Internal Med Res Open J Volume 1(2): 1-4 